\title{
Hubungan Antara Aktiviti Fizikal dan Indeks Jisim Badan Murid Lelaki Luar Bandar
}

\section{(The Relationship Between Physical Activities and Body Mass Index of Male Students in Rural)}

\author{
Mohd Khushairy Bakhtiar Afindi ${ }^{*}$, Mohd Radzani Abd Razak², Erwan Ismail ${ }^{3}$ \\ ${ }^{1}$ Fakulti Pendidikan, Universiti Kebangsaan Malaysia (UKM), 43600, Bangi, Selangor, Malaysia. \\ Email: mohdkhushairy86@gmail.com \\ ${ }^{2}$ Fakulti Pendidikan, Universiti Kebangsaan Malaysia (UKM), 43600, Bangi, Selangor, Malaysia. \\ Email: mohd.radzani@gmail.com \\ ${ }^{3}$ Fakulti Pendidikan, Universiti Kebangsaan Malaysia (UKM), 43600, Bangi, Selangor, Malaysia. \\ Email: erwanismail245@gmail.com
}

\section{CORRESPONDING \\ AUTHOR (*): \\ Mohd Khushairy Bakhtiar \\ Afindi \\ (mohdkhushairy86@gmail.com)}

KATA KUNCI:

Aktiviti fizikal

Indeks Jisim Badan (BMI)

Global Physical Activity

Questionnaire (GPAQ)

\section{KEYWORDS:}

Physical activities

Body Mass Index (BMI)

Global Physical Activity

Questionnaire (GPAQ)

\section{CITATION:}

Mohd Khushairy Bakhtiar Afindi, Mohd Radzani Abd Razak, \& Erwan Ismail. (2022). Hubungan Antara Aktiviti Fizikal dan Indeks Jisim Badan Murid Lelaki Luar Bandar. Malaysian Journal of Social Sciences and Humanities (MJSSH), 7(2), e001294. https://doi.org/10.47405/mjssh.v7i2.1294

\begin{abstract}
ABSTRAK
Aktiviti fizikal dan kecergasan merupakan perkara yang perlu diambil berat dalam kehidupan seharian bagi menjamin kesihatan tubuh badan serta mendapat Indeks Jisim Badan (BMI) yang ideal. Tujuan kajian ini adalah untuk mengkaji hubungan antara aktiviti fizikal dan indeks jisim badan (BMI) murid lelaki sekolah menengah di luar bandar. Populasi kajian terdiri daripada (390) pelajar lelaki tingkatan 5 di daerah Tampin. Kajian berbentuk tinjauan ini menggunakan borang soal selidik yang diubahsuai daripada Global Physical Activity Questionnaire (GPAQ) oleh World Health Organization (WHO). Kajian ini mendapati bahawa murid-murid lelaki di daerah Tampin adalah tidak aktif dalam aktiviti fizikal walaupun memiliki bacaan BMI normal. Kesannya, mereka cenderung untuk memiliki risiko kesihatan yang rendah.
\end{abstract}

\section{ABSTRACT}

Physical activities and fitness should be prioritized in order to guarantee healthy body and obtain as well as maintain the ideal Body Mass Index (BMI). This research aimed at studying the relationship between physical activities and BMI of secondary school male students in rural areas. The research population are 390 Form 5 male students in Tampin district which were selected using stratified random sampling method. 180 research sample were then selected through Krecjie and Morgan sample size determination table (1970). This survey-based research utilises a questionnaire modified from Global Physical Activity Questionnaire (GPAQ) by World Health Organisation (WHO). This research shows that male students in Tampin district are not active in physical activities despite having normal BMI readings. As a result, they tend to have low health risk. 
Sumbangan/Keaslian: Kajian ini menyumbang kepada literatur sedia ada yang mengkaji hubungan antara aktiviti fizikal dan indeks jisim badan murid lelaki luar bandar berpaksikan metod kuantitatif yang menggunakan kaedah soal selidik.

\section{Pengenalan}

Aktiviti fizikal dan kecergasan merupakan perkara yang perlu diambil berat dalam kehidupan seharian bagi menjamin kesihatan tubuh badan serta mendapat Indeks Jisim Badan (BMI) yang ideal. Aktiviti fizikal adalah sebarang aktiviti yang dilakukan oleh badan melalui pergerakan yang melibatkan penggunaan tenaga dalam diri individu secara keseluruhan berkait rapat dengan kesihatan dan kesejahteraan. Senaman dan aktiviti fizikal merupakan satu cabang penting dalam penjagaan kesihatan dan bentuk badan seseorang selepas mempunyai diet yang betul dan berfaedah dalam membantu meningkatkan kualiti hidup.

Kajian ini adalah untuk mengenal pasti hubungan indeks jisim badan dan corak aktiviti fizikal pelajar lelaki luar bandar di daerah Tampin, Negeri Sembilan. Aktiviti fizikal yang tidak efisien akan semasa usia muda akan memberi kesan yang negatif kepada tahap kesihatan pada masa depan. Pengamalan gaya hidup sihat ini tidak terbatas kepada hanya memberi kesihatan sahaja, malah akan dapat memberikan kesejahteraan kepada mental, membina bentuk tubuh yang menarik seterunya dapat meningkatkan keyakinan diri (Caspersen et al., 2000). Kajian Dan et al. (2011) juga menunjukkan bahawa murid yang berumur 13 hingga 14 tahun gemar melakukan aktiviti fizikal berintensiti sederhana. Oleh itu, kajian ini memfokuskan corak aktiviti fizikal dan tahap kesihatan.

Bhadoria et al (2015) mendapati bahawa obesiti dalam kalangan kanak-kanak menjadi isu kesihatan yang serius di mana dianggarkan 42 juta orang kanak-kanak Asia yang berumur bawah 5 tahun adalah dikategorikan dalam berat berlebihan. Ini menunjukkan hubungan rapat antara aktiviti fizikal dan kecergasan dengan kesihatan seseorang atlet 12 tahun ke bawah. Cadangan daripada Pertubuhan Kesihatan Sedunia (WHO) kanakkanak dan warga muda berumur 5 hingga 17 tahun perlu menjalankan aktiviti fizikal yang sederhana hingga berintensiti tinggi dalam jangka masa 60 minit setiap hari.

Kebanyakan kajian yang lepas memfokuskan kajian di kawasan-kawasan padat penduduk atau kawasan-kawasan bandar di mana aktiviti fizikal yang lebih berbeza berbanding aktiviti fizikal seperti di luar bandar atau di pedalaman Sabah dan Sarawak. Gaya hidup kanak-kanak bawah 12 tahun di luar bandar jauh berbeza dari segi pemakanan dan juga aktiviti fizikal harian mereka. Tujuan kajian ini adalah untuk mengkaji aktiviti fizikal dan indeks jisim badan (BMI) murid lelaki sekolah menengah di luar bandar. Kajian ini dapat membantu murid, pihak sekolah,jabatan-jabatan pendidikan dan kementerian dalam mereka bentuk atau merangka program untuk meningkatkan tahap kesedaran kepentingan aktiviti fizikal yang baik dan tersusun serta berterusan dalam melahirkan murid yang sihat dan seimbang.

\section{Sorotan Literatur}

Aktiviti fizikal dikategorikan kepada tiga jenis iaitu aktiviti fizikal berintensiti rendah (light-intesity physical activity) (LPA), aktiviti fizikal berintensiti sederhana (moderateintensity physical acivity) (MPA), dan aktiviti fizikal berintensiti tinggi (vigarous-intensty 
physical activity) (VPA) (Ainsworth et al., 2000; USDHHS 2018). Aktiviti fizikal dikaitkan dengan pelbagai manfaat kesihatan dan pengurangan risiko penyakit. Timperio et al. (2000) melakukan kajian berkaitan dengan kepercayaan dan gelagat aktiviti fizikal dalam kalangan dewasa yang cuba mengawal berat badan. Pengkaji melaporkan bahawa berjalan merupakan aktiviti biasa yang dilakukan oleh golongan dewasa dalam mengawal berat badan. Walau bagaimanapun, golongan lelaki dan perempuan masih tidak menyedari nilai atau manfaat melakukan MPA dengan sepenuhnya. Pengkaji mencadangkan bahawa, pendedahan atau promosi MPA haruslah digalakkan dalam aktiviti kawalan berat badan terutamanya sebarang aktiviti yang boleh dilakukan di luar aktiviti yang dirancang.

Gaya hidup kanak-kanak bawah 12 tahun diluar bandar jauh berbeza dari segi pemakanan dan juga aktiviti fizikal harian mereka. Menurut Erwin dan Radzani (2021) ini dibuktikan melalui Kajian Kesihatan dan Morbiditi Kebangsaan 2006 menunjukkan 43.7 peratus rakyat Malaysia tidak menjalankan hidup secara aktif. Kajian yang sama juga menunjukkan $45.6 \%$ orang dewasa di kawasan luar bandar kurang aktif berbanding dengan orang dewasa di kawasan bandar. Kajian ini juga menunjukkan terdapat kira-kira $43 \%$ orang dewasa, $20 \%$ remaja dan $26 \%$ pelajar sekolah rendah mengalami berat badan yang berlebihan atau obes. Penglibatan yang aktif dalam apa sahaja aktiviti fizikal tidak dapat dinafikan boleh mengurangkan risiko mendapat penyakit diabetes, penyakit serangan jantung, masalah tekanan darah tinggi, masalah kerapuhan tulang dan masalah berat badan berlebihan di samping mampu meningkatkan kecergasan diri seseorang (Warburton et al., 2006; Tremblay et al., 2011).

Promosi dalam menggalakkan penglibatan melakukan aktiviti fizikal pada semua peringkat usia dari muda sehingga tua sangat penting untuk kesejahteraan hidup. Ini adalah disebabkan oleh peningkatan populasi obesiti rakyat di Malaysia amnya dan dunia umumnya. Kamarudin et al. (2007) melakukan kajian dengan menilai sikap secara umum ke atas pelajar kolej ke arah mata pelajaran Pendidikan Jasmani di Kuala Lumpur. Khususnya, 113 pelajar berusia 19 hingga 25 tahun dikaji untuk menentukan sikap mereka dalam aktiviti fizikal. Hasil kajian mendapati bahawa pelajar lelaki mendapat nilai paling tinggi dari segi pengetahuan umum dan asas saintifik aktiviti fizikal mereka. Selain itu, kajian menunjukkan terdapat perbezaan penglibatan antara jantina dalam kelas pendidikan jasmani.

Laporan National Institutes of Health (NIH) (2019) mendapati bahawa satu daripada empat orang yang berumur antara 16 tahun dan ke atas adalah tidak aktif melakukan aktiviti secara fizikal dan ini sejajar dengan dapatan daripada World Health Organization (2002) ketidakaktifan secara fizikal merupakan penyumbang ke-empat (ke-4) ke atas risiko kematian di seluruh dunia. Dapatan NIH juga menunjukkan bahawa perempuan merupakan antara golongan yang tidak aktif iaitu sebanyak 28\% (National Institutes of Health, 2019). NIH turut melaporkan bahawa sektor pekerjaan yang merujuk kepada pelajar adalah yang paling tidak aktif iaitu 39\% berbanding sektor pekerjaan lain serta lokaliti yang paling tidak aktif adalah di luar bandar iaitu sebanyak $27 \%$.

Kajian ini berfokuskan untuk mengkaji hubungan aktiviti fizikal dan indeks jisim badan murid lelaki luar bandar. Oleh itu, aktiviti fizikal dan kecergasan kesihatan memainkan peranan yang penting dalam meminimumkan risiko wabak penyakit seperti jantung, kolesterol, dan penyakit kronik yang lain di samping dapat melahirkan masyarakat yang sihat dan tidak obesiti serta dapat meningkatkan jangka hayat individu. Penglibatan murid dalam melakukan aktiviti fizikal secara tidak langsung juga dapat meningkatkan 
tahap keyakinan diri, kecerdasan mental, pembentukan fizikal yang baik, dan mampu berdaya saing serta menjadi murid yang lebih kreatif dan berinovatif.

\section{Metod Kajian}

Populasi kajian ini terdiri daripada murid lelaki luar bandar di sekolah yang telah ditakrifkan sekolah luar bandar oleh pihak Kementerian Pendidikan Malaysia (KPM). Peringkat umur yang ditumpukan adalah murid berumur antara 17 tahun. Hal ini demikian kerana peringkat umur ini mempunyai tahap pemahaman yang lebih tinggi berbanding peringkat umur yang lain di peringkat sekolah. Kajian yang dijalankan ini merupakan kajian kuantitatif yang berbentuk tinjauan.

Dalam kajian ini, penyelidik menggunakan pensampelan rawak berstrata. Penggunaan pensampelan ini terpilih kerana timbul kesulitan untuk mendapatkan senarai ahli populasi dan tiada peruntukan untuk ke semua lokasi kajian dan populasi adalah berselerak (homogeneous). Sampel yang dipilih adalah mewakili sampel lain yang tidak dilibatkan dalam kajian yang mana pengkaji membuat pembahagian mengikut sekolah.

Seramai 180 orang murid lelaki tingkatan lima yang berumur 17 tahun yang terlibat dengan menggunakan kaedah penentuan sampel adalah menggunakan jadual penentuan sampel Krejcie dan Morgan (1970) dan menggunakan kaedah pensampelan (rawak) berstrata. Instrumen kajian terdiri daripada borang selidik Global Physical Activity Questionnair (GPAQ). Soal selidik GPAQ diperkenalkan oleh World Health Organization (WHO, 2002) dan telah diubahsuai dalam mengikut kesesuaian kajian. Borang soal selidik GPAQ versi II mempunyai tiga konstruk utama iaitu aktiviti bekerja atau sekolah, aktiviti perjalanan, dan aktiviti rekreasi atau senggang. Kebolehpercayaan dalam kajian ini dijalankan berdasarkan item di dalam konstruk utama borang soal selidik yang terdiri daripada aktiviti VPA waktu bekerja atau sekolah, aktiviti MPA waktu bekerja atau sekolah, perjalanan dari atau ke suatu destinasi, aktiviti VPA waktu rekreasi atau senggang, aktiviti MPA waktu rekreasi atau senggang, dan aktiviti sedentari. Tahap kebolehpercayaan dapat ditentukan melalui interpretasi nilai alpha Cronbach $(\alpha)$.

Pada fasa pertama iaitu fasa maklumat populasi kajian, pengkaji mendapatkan data mentah berkaitan dengan jumlah sekolah luar bandar dan murid lelaki berumur 17 yang terdapat di dalam daerah Tampin melalui Pejabat Pendidikan Daerah Tampin. Fasa kedua, pengkaji mendapatkan kelulusan menjalankan penyelidikan dengan pihak sekolah. Fasa ketiga adalah merujuk kepada borang soal selidik. Setelah mendapatkan kelulusan daripada semua pihak, pengkaji meminta bantuan dari guru-guru pendidikan jasmani yang telah diberikan penerangan soal selidik tersebut. Guru mengedarkan borang soal selidik kepada murid. Murid perlu menjawab borang soal selidik yang diedarkan. Borang soal selidik dibahagikan kepada empat bahagian. Bahagian pertama adalah berkaitan dengan latar belakang demografi (13 item), bahagian kedua adalah berkaitan dengan kesihatan umum ( 9 item), bahagian ketiga adalah berkaitan dengan aktiviti fizikal (16 item). Murid perlu menjawab kesemua item dalam masa 30 minit dengan dibantu oleh guru dan borang soal selidik diterangkan secara terperinci supaya murid jelas dan faham.

Fasa keempat adalah merujuk kepada fasa penilaian tahap kesihatan pelajar berdasarkan BMI pelajar. Pelajar akan diukur ketinggian dan diambil berat badan untuk membuat kiraan BMI. Ia dibentuk bagi mengenal pasti corak aktiviti (tinggi, sederhana, rendah) melalui empat domain utama iaitu berdasarkan situasi harian waktu di sekolah, perjalanan ke atau dari sesuatu tempat, aktiviti rekreasi dan tingkah laku sedentari 
(duduk). Soalan yang terkandung dalam bahagian ini akan memberikan data mengenai hari, jam dan minit dalam melakukan tiga corak aktiviti fizikal tersebut. Penilaian responden pula adalah berdasarkan skala sela.

Oleh itu, dengan menggunakan nilai MET kepada tahap aktiviti membolehkan kita untuk mengira jumlah aktiviti fizikal. Bagi menganalisis data GPAQ, persamaan metabolik nilai (MET) telah digunakan: aktiviti berintensiti rendah $=1.0 \mathrm{MET}$, aktiviti berintensiti sederhana $=4.0 \mathrm{MET}$, dan aktiviti berintensiti tinggi $=8.0 \mathrm{MET}$. Nilai MET per minit seminggu (MET-min minggu-1) dikira seperti berikut: minit aktiviti / hari $\times$ hari seminggu $\times$ tahap MET. Jumlah skor aktiviti fizikal diperoleh dari GPAQ telah dikelaskan kepada 3 kategori untuk setiap tahap aktiviti fizikal individu yang rendah, sederhana atau tinggi mengikut protokol jaringan pada GPAQ berdasarkan garis panduan bagi menganalisis GPAQ.

\section{Hasil Kajian}

Dapatan analisis deskriptif menunjukkan bahawa 180 orang murid dikaji terdiri daripada pelajar lelaki. Kebanyakan murid adalah beragama Islam iaitu 67.8\%, Buddha $14.4 \%$ dan $17.8 \%$ adalah beragama Hindu. Sektor pekerjaan bapa yang tertinggi dalam kalangan murid luar adalah bekerja sendiri iaitu 52.2\% dan sektor pekerjaan ibu tertinggi adalah tidak bekerja iaitu $61.1 \%$ dengan purata pendapatan keluarga adalah kurang daripada RM1,000.00 iaitu 46.7\%.

Penggunaan kereta merupakan pengangkutan ke sekolah yang paling tinggi iaitu 68.3\% manakala jarak $1 \mathrm{~km}-10 \mathrm{~km}$ dari rumah ke sekolah mencatatkan $72.8 \%$. Hasil dapatan juga mendapati bahawa $10 \%$ bukan atlet dan mempunyai tahap penglibatan dalam sukan tertinggi adalah peringkat sekolah 65.6\%. Jadual 1 menunjukkan hasil analisis deskriptif latar belakang demografi murid luar bandar daerah Tampin.

Jadual 1: Analisis deskriptif latar belakang demografi murid

\begin{tabular}{llllll}
\hline Kategori & Kekerapan & $\begin{array}{l}\text { Peratus } \\
\text { (\%) }\end{array}$ & S.P. & Min \\
\hline Agama & Islam & 122 & 67.8 & 0.78 & 1.5 \\
& Budhha & 26 & 14.4 & & \\
Sektor Pekerjaan & Hindu & 32 & 17.8 & & \\
Bapa & Kerajaan & 35 & 19.4 & 0.929 & 2.55 \\
& Swasta & 31 & 17.2 & & \\
& Sendiri & 94 & 52.2 & & \\
Sektor Pekerjaan Ibu & Tidak Bekerja & 20 & 11.1 & & \\
& Kerajaan & 34 & 18.9 & 1.166 & 3.21 \\
& Swasta & 5 & 208 & & \\
Pendapatan Purata & Sendiri & 31 & 17.2 & & \\
Ibu Bapa & Tidak Bekerja & 110 & 61.1 & & \\
& < RM 1000.00 & 84 & 46.7 & 1.443 & 2.18 \\
& RM1000.01- & 42 & 23.3 & & \\
& RM2000.00 & & & & \\
& RM2000.01- & 17 & 9.4 & & \\
& RM3000.00 & & & & \\
& RM3000.01- & 11 & 6.1 & & \\
& RM4000.00 & 26 & 14.4 & & \\
\hline
\end{tabular}




\begin{tabular}{llllll}
\hline Cara Pengangkutan & Jalan Kaki & 9 & 5 & 0.713 & 2.83 \\
& Motosikal & 32 & 17.8 & & \\
& Kereta & 123 & 68.3 & & \\
& Bas & 12 & 6.7 & & \\
Jarak Dari Rumah & Basikal & 4 & 2.2 & & \\
Ke Sekolah & $10 \mathrm{KM}$ & 131 & 72.8 & 0.527 & 2.3 \\
& $11-20 \mathrm{KM}$ & 45 & 25 & & \\
Tahap Penglibatan & $21-30 \mathrm{KM}$ & 3 & 1.7 & & \\
Sukan & $50 \mathrm{KM}$ & 1 & 0.6 & & \\
& Tiada Penglibatan & 18 & 10 & 0.781 & 1.24 \\
& Sekolah & 118 & 65.5 & & \\
& MSSD & 28 & 1.6 & & \\
& MSS Negeri & 14 & 7.8 & & \\
& MSSM & 2 & 1.1 & & \\
\hline
\end{tabular}

Dapatan tahap penglibatan aktiviti fizikal MPA menunjukkan bahawa murid yang kurang aktif lebih tinggi berbanding pelajar aktif, iaitu pelajar yang kurang aktif sebanyak $41.1 \%$ dan pelajar aktif sebanyak 25\%. Bagi tahap penglibatan aktiviti fizikal VPA 51.7\% adalah tidak aktif manakala tahap penglibatan aktiviti fizikal mingguan TPA menunjukkan pelajar aktif sebanyak 46.7\%. Dapatan menunjukkan kategori aktiviti sedentari tinggi $30.6 \%$ dan rendah 69.4\%. Jadual 2 menunjukkan analisis deskriptif bagi tahap penglibatan murid luar bandar daerah Tampin.

Jadual 2: Analisis deskriptif bagi tahap penglibatan murid dalam aktiviti fizikal

\begin{tabular}{llllll}
\hline Kategori & $\begin{array}{l}\text { Klasifikasi Aktiviti } \\
\text { Fizikal }\end{array}$ & $\begin{array}{l}\text { Kekerapan } \\
\text { (N) }\end{array}$ & $\begin{array}{l}\text { Peratusan } \\
\text { (\%) }\end{array}$ & S.P. & Min \\
$\begin{array}{l}\text { Tahap Penglibatan } \\
\text { Aktiviti }\end{array}$ & Tidak Aktif & 61 & 33.9 & 0.764 & 1.91 \\
Fizikal MPA & Kurang Aktif & 74 & 41.1 & & \\
Tahap Penglibatan & Aktif & 45 & 25 & & \\
Aktiviti & Tidak Aktif & 93 & & & \\
Fizikal VPA & Kurang Aktif & 38 & 51.7 & 1.76 & 0.856 \\
& Aktif & 49 & 27.1 & & \\
Tahap Penglibatan & Tidak Aktif & 52 & & & \\
Aktiviti Fizikal & Kurang Aktif & 44 & 28.9 & 2.18 & 0.853 \\
Mingguan TPA & Aktif & 84 & 46.7 & & \\
Kategori Aktiviti & Tinggi & 55 & & & \\
Sedantari & Rendah & 125 & 69.4 & & \\
& & & & & \\
\hline
\end{tabular}

Bagi indeks jisim badan (BMI) dapat diklasifikasikan BMI yang normal iaitu 71.1\%, berat badan berlebihan $15 \%$, obesiti $7.8 \%$ dan $6.1 \%$ ialah kurang berat secara keseluruhan dengan min BMI adalah 21.68kgm-2. Jadual 3 menunjukkan analisis deskriptif bagi indeks jisim badan murid keseluruhan 
Jadual 3: Analisis deskriptif bagi indeks jisim badan murid

\begin{tabular}{|c|c|c|c|c|c|}
\hline Kategori & Klasifikasi BMI & $\begin{array}{l}\text { Kekerapan } \\
\text { (N) }\end{array}$ & $\begin{array}{l}\text { Peratusan } \\
(\%)\end{array}$ & S.P. & $\begin{array}{l}\text { Min } \\
\left(\mathrm{kgm}^{-2}\right)\end{array}$ \\
\hline \multirow[t]{4}{*}{ Keseluruhan } & Obesiti & 14 & 7.8 & 1.007 & 21.68 \\
\hline & Berat Berlebihan & 27 & 15 & & \\
\hline & Kurang Berat & 11 & 6.1 & & \\
\hline & Normal & 128 & 71.1 & & \\
\hline
\end{tabular}

Hasil kajian korelasi Pearson mendapati bahawa tahap penglibatan aktiviti fizikal mingguan TPA tidak mempunyai hubungan yang signifikan terhadap BMI dalam di kalangan murid iaitu $r=0.007 ; p>0.05=0.929$. Jadual 4 menunjukkan analisis kolerasi Pearson antara tahap penglibatan aktiviti fizikal mingguan TPA terhadap BMI

Jadual 4: Analisis Kolerasi Pearson antara tahap penglibatan aktiviti fizikal mingguan TPA terhadap BMI

\begin{tabular}{lll}
\hline Kategori & & BMI \\
\hline Tahap Penglibatan Aktiviti & Korelasi Pearson & 0.007 \\
Fizikal Mingguan TPA & Sig (2-tailed) & 0.929 \\
& N & 180 \\
\hline
\end{tabular}

**Hubungan yang signifikan pada tahap 0.05 (2-tailed)

\section{Perbincangan Kajian}

Kesihatan seseorang dipengaruhi oleh tahap penglibatan aktiviti fizikal semakin aktif seseorang maka bertambah baik kesihatan. Tujuan kajian ini mengkaji aktiviti fizikal dan indeks jisim badan (BMI) murid lelaki sekolah menengah di luar bandar di daerah Tampin, Negeri Sembilan. Secara keseluruhannya, aktiviti fizikal murid lelaki Tingkatan 5 di daerah Tampin berada pada tahap tidak aktif walaupun mempunyai BMI yang normal. Kesannya, mereka cenderung untuk memiliki risiko kesihatan yang rendah iaitu $71.1 \%$ secara keseluruhan dengan min BMI adalah 21.68kgm-2. Dapatan ini selari dengan kajian Erwan dan Mohd Radzani (2017) juga menunjukkan yang mana murid di FELDA turut melakukan aktiviti fizikal berintensiti sederhana dan tahap kecergasannya adalah sederhana cergas.

\section{Kesimpulan}

Kesimpulannya murid luar bandar di daerah Tampin adalah tidak aktif kerana hanya bergantung pada pembelajaran Pendidikan Jasmani dan aktiviti kokurikulum di sekolah sahaja. Mata pelajaran Pendidikan Jasmani di sekolah sahaja tidak mencukupi untuk mengekalkan tahap kesihatan murid kerana ianya hanya menekankan aspek teknikal dan ilmu pengetahuan dan bukannya kecergasan murid. Semasa kajian ini dijalankan, Covid19 telah melanda dunia dan Malaysia juga tidak terkecuali. Ini menyebabkan murid tidak dapat melakukan aktiviti di luar rumah. Selain itu, murid lebih berminat dengan bermain permainan secara dalam talian daripada berada di luar rumah untuk melakukan aktiviti fizikal atau untuk riadah bersama rakan-rakan serta keluarga.

Oleh hal yang demikian, saya mencadangkan agar kajian akan datang dapat mencari penyelesaian yang lain bagi menggalakkan murid-murid untuk lebih minat dan aktif dalam melakukan aktiviti fizikal dengan mentransformasikan bidang kurikulum dan 
kokurikulum di sekolah mengikut keadaan semasa dalam melahirkan murid yang lebih cergas dari segi mental dan fizikal di masa hadapan.

\section{Penghargaan (Acknowledgement)}

Saya mengucapkan sepenuh penghargaan kepada Dr Radzani bin Abdul Razak kerana meletakkan kepercayaan beliau kepada saya untuk menyiapkan artikel ini dalam tempoh yang ditetapkan beliau telah banyak membantu sepanjang proses tugasan ini disiapkan.

\section{Kewangan (Funding)}

Kajian dan penerbitan ini tidak menerima sebarang tajaan atau bantuan kewangan daripada mana-mana pihak.

\section{Konflik Kepentingan (Conflict of Interests)}

Penulis tidak mempunyai konflik kepentingan dalam menjalankan kajian dan penerbitan artikel ini.

\section{Rujukan}

Ainsworth, B. E., Haskell, W. L., Whitt, M. C., Irwin, M. L., Swartz, A. M., Strath, S. J., O???Brien, W. L., Bassett, D. R., Schmitz, K. H., Emplaincourt, P. O., Jacobs, D. R., \& Leon, A. S. (2000). Compendium of Physical Activities: an update of activity codes and MET intensities. Medicine \& Science in Sports \& Exercise, 32(Supplement), S498S516. https://doi.org/10.1097/00005768-200009001-00009

Bhadoria, A. S., Sahoo, K., Sahoo, B., Choudhury, A. K., Sufi, N. Y., \& Kumar, R. (2015). Childhood obesity: Causes and consequences. Journal of Family Medicine and Primary Care, 4(2), 187. https://doi.org/10.4103/2249-4863.154628

Caspersen, C.J., Pereira, M.A., \& Curran, K.M. 2000. Changes in physical activity patterns in the United States, by sex and cross-sectional age. Medicine \& Science in Sports and Exercise, 32(9), 1601-1609.

Dan, S. P., Mohd Nasir, M. T., \& Zalilah, M.S. (2007). Sex and ethnic differentials in physical Activity levels of adolescents in kuantan. Malaysia Journal of Nutrition, 13(2), 10920. Retrieved from http://www.ncbi.nlm.nih.gov/pubmed/22691749

Erwan Ismail \& Mohd Radzani Abdul Razak (2017). Tahap Kecergasan Fizikal Berlandaskan Kesihatan dan Corak Aktiviti Fizikal Murid Sekolah di Gugusan FELDA. Seminar Serantau 2017, 1052-1056.

Erwin, M., \& Radzani, R. (2021). Tahap Penglibatan Aktiviti Fizikal dan Kecergasan Fizikal Dalam Kalangan Pemain Bola Sepak di Kapit, Sarawak. Jurnal Dunia Pengurusan, 3(1), 150-158.

Kamarudin, Kamaria \& Omar-Fauzee, Mohd. Sofian. (2007). Attitudes toward physical activities among college students. Pakistan Journal of Psychological Research, 22(12), 43-54.

Krejcie, R. V., \& Morgan, D. W. (1970). Determining sample size for research activities. Educational and psychological measurement, 30(3), 607-610

National Institutes of Health (NIH). (2019). Key findings of National Health and Morbidity Survey 2019 Non-communicable diseases, healthcare demand, and health literacy. National Health and Morbidity Survey 2019. 
https://iptk.moh.gov.my/images/technical_report/2020/4_Infographic_Booklet_N HMS_2019_-_English.pdf

Timperio, A., Cameron-Smith, D., Burns, C., Salmon, J. \& Crawford, D. 2000. Physical activity beliefs and behaviors among adults attempting weight control. International Journal of Obesity, 24(1), 81- 87.

Tremblay, M. S. et al. (2011). New Canadian physical activity guidelines. Applied Physiology, Nutrition, and Metabolism, 36(1), 36-46.

Warburton, D. E. R., C. W. Nicol \& S. S. D. Bredin (2006). Health benefits of physical activity: The evidence. Canadian Medical Association Journal, 174(6), 801-809.

World Health Organization (2002). Global Physical Activity Questionnaire (GPAQ): Analysis Guide. Geneva: World Health Organization. Diperoleh daripada www.who.int/chp/steps 